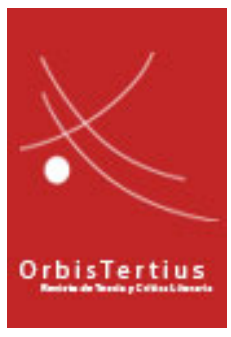

Orbis Tertius, vol. XXIII, $\mathrm{n}^{\circ}$ 27, e078, junio 2018. ISSN 1851-7811

Universidad Nacional de La Plata

Facultad de Humanidades y Ciencias de la Educación

Centro de Estudios de Teoría y Crítica Literaria

\title{
Sobre Sánchez, una biografía perezosa
}

\section{Julia Musitano *}

* Universidad Nacional de Rosario, Argentina.

Cita sugerida: Musitano, J. (2018). Sobre Sánchez, una biografía perezosa. Orbis Tertius, 23 (27), e078. https://doi.org/10.24215/18517811e078 


\title{
Sobre Sánchez, una biografía perezosa
}

\author{
Julia Musitano \\ Universidad Nacional de Rosario, Argentina
}

\begin{abstract}
Resumen:
En este trabajo, me interesa resaltar la escritura biográfica de Osvaldo Baigorria (Sobre Sánchez) para pensar el vínculo entre biografia y literatura, por un lado, y la relación entre biógrafo y biografiado, por otro. La biografia de escritor (un escritor que escribe sobre otro escritor) puede definirse por la potencia imaginaria que une la obra y la vida del biografiado. Por eso, es importante observar allí el sentido de la aparición de lo autobiográfico: de la intromisión, a veces discreta a veces impune, del biógrafo en la vida del sujeto biografiado en proceso de construcción (el tercer capítulo de la biografía o "las notas al pie" constituyen la parte autorreferencial del texto), y simultáneamente la intrusión de la vida y la literatura del biografiado en los relatos del biógrafo (pienso en Con el sudor de tu frente y Anarquismo transhumante de Baigorria). Y, a partir de esto, específicamente, en Sobre Sánchez, quiero indagar en la elección de escribir sobre Néstor Sánchez y no sobre otro escritor y en la tensión entre el trabajo que conlleva la investigación de una vida y la pereza con la que construye Baigorria a su biografiado.
\end{abstract}

Palabras Clave: biografia - Osvaldo Baigorria - Néstor Sánchez-pereza - autofiguración.

\begin{abstract}
:
I am interested in outliningThis article outlines the biographical writing of Osvaldo Baigorria (Sobre Sánchez) in order to think aboutcontemplate the relationship connection between biography and literature, on the one sidehand, and between a biographer and its subjecta biographee, on the other. A writer's biography (a writer who writes about another writer's life) could define itself as the imaginary force that links the subject's life and work. That is the reason why it is important to observe there the meaning of the autobiographical emergencey of the autobiographical: the biographer's discreet or blatant intromission intrusion of the biographer into the life of itsthe subject's life in during the construction process (the third chapter of Sobre Sánchez or "las notas al pie" is the self-writing referential part of the text), and also the simultaneous intromission intrusion of the subject's life and literature into the biographer'swriting of the writing biographer (I am thinking onfor instance, Con el sudor de tu frente and Anarquismo transhumante by Baigorria). I would like to inquire into Baigorria 's choice to write about Néstor Sánchez, and not aboutrather than someone elseany other writer, and into the tension between the work efforts involved in researching a life and the laziness with which Baigorria builds its his subject.
\end{abstract}

KEYWORDs: biography - Osvaldo Baigorria - Néstor Sánchez z - laziness - self-figuration .

Tengo fiaca. $\mathrm{O}$ tal vez alergia al trabajo. $\mathrm{O}$ me dio un ataque de pereza

O. Baigorria, "Preferiría no escribirlo"

Osvaldo Baigorria escribió dos novelas: Llévatela, amigo, por el bien de los tres (1989) y Correrías de un infiel (2005), ambas en primera persona y con un tinte evidentemente autobiográfico. En la primera, relata la historia de amor de Lila y Eduardo, una pareja abierta y nómade, a través de sus recuerdos sexuales; en la segunda utiliza un personaje con su mismo nombre para ir en búsqueda de un tío, antecedente cacique de los indios ranqueles a través de una reescritura de Mansilla. También escribió un libro de crónicas Anarquismo trashumante (2008) en el que cuenta anécdotas de crotos y de linyeras empezando por la de su propio padre. Prologó un libro de ensayos, Con el sudor de tu frente (1995/2008), que reúne textos de Barthes, Adorno, Wilde, Stevenson, entre otros, sobre la pereza, la fiaca, el no hacer nada. El prólogo se titula "Preferiría no escribirlo". Por último, en 2012, publicó Sobre Sánchez, la biografía que hoy me ocupa. La biografía de un escritor, Néstor Sánchez, que había publicado varias novelas en la década del 60 en Argentina y que iba camino 
a convertirse en otro Manuel Puig, pero que un buen día desapareció de la faz de la tierra. Luego de varios años de búsqueda, se supo que, durante los 70, había deambulado por varios países y que, en ese momento, vivía como clochard, croto o vagabundo en una playa de estacionamiento en Los Ángeles tal como lo había hecho antes en París y Nueva York. En el 80, volvió a Argentina destrozado y sin ninguna pertenencia más que un bolso con los documentos y un piyama. Escribió, en el 90, La condición efímera, libro en el que venía trabajando desde su temporada en Estados Unidos, y después de su publicación renunció a seguir escribiendo. No quiso escribir más hasta su muerte en el 2003.

Después de leer la biografía, me surgieron varias inquietudes (debo confesar que esta biografía particularmente me despertó una serie de curiosidades que debí inmediatamente satisfacer, como leer la obra completa de Baigorria, leerlo a Sánchez, indagar en la concepción de una pareja abierta, preguntarme sobre escritores que renuncian a escribir, y algunas cosas más que ahora se dispersaron) que voy a intentar ordenar aquí: como ocurre a menudo que se lee una biografía, la primera cuestión que se me planteó fue por qué Baigorria elige escribir sobre Sánchez, un escritor nómade e inapresable. Por encargo, por dinero, por trabajo, dice en la biografía. ¿ Por qué este escritor y no otro? Y la segunda es por qué transformó la decisión de dejar de escribir en cifra de la vida de Sánchez, se concentra en la renuncia indeclinable de Sánchez a seguir escribiendo. La clave de la vida del biografiado está en eso que no hizo, que dejó de hacer. Cuando continué la lectura de la obra de Baigorria —seguí por Llévatela amigo, las crónicas y los ensayos- me percaté de que el biógrafo busca en su modo de hacer literatura una forma que se conecta directa y explícitamente con el no. "Preferiría no escribirlo" se llama el prólogo a Con el sudor de tu frente, y las crónicas, que se reeditaron, ampliaron y reescribieron, muestran un interés marcado por la vida del nómade, del que se va porque quiere, del que prefiere no tener un hogar, del que vive en la intemperie. Entonces, Sobre Sánchez se presentó ante mí casi como una epifanía, como aquello que buscaba desde mi trabajo sobre Fernando Vallejo ${ }^{1}$ : un biógrafo que construye un biografiado a su imagen y semejanza, que deja que su propia literatura ingrese sin pedir permiso en la vida de otro, y que simultáneamente le permite al otro colarse en los intersticios de su obra.

Una biografía literaria no tiene la necesidad de retratar las grandes hazañas de un sujeto, sino que se focaliza en los hechos menores, dice Patricio Fontana, en los que el biógrafo captará aquello por lo cual quiere relatar una vida. Encontrar el sentido de la vida dispersa de Sánchez a partir del saber disponible sobre él, y no en grandes acontecimientos, se convirtió en un problema metodológico para Baigorria. Tanto es así que la biografía comienza con una página, titulada "About", en la que advierte que el libro atravesó varias versiones y cambios de género, "de biografía fallida a ensayo colapsado con astillas de novela a medio terminar a postautobiografía” (2012:7).

Baigorria divide la biografía en tres capítulos "Voodoo child", “The Néstor Sánchez experience” y "Notas al pie"; en "About" advierte que el lector puede leer las notas al pie como lo que son, o como tercer capítulo. Esas notas conforman la parte autoreferencial del texto, en la que Baigorria cuenta su experiencia nómade en los Estados Unidos y la variedad de trabajos que le permitieron sobrevivir. Aunque Baigorria se resista a definir su libro como una biografía y lo describa como una postautobiografía, Sobre Sánchez es una biografía literaria porque presenta al biografiado en su potencia imaginaria, como posibilidad de vida. El punto clave para definirla como biografía literaria está en la forma que el biógrafo decide darle a esos datos con los que trabaja, en cómo muestra "el movimiento de una vida y la trayectoria de un pensamiento", dice Benoît Peeters (2010: 54).

La biografía de escritor no se define ni por una interpretación analítico-crítica de sus textos, ni por un modo de retratar la época en la que ese escritor vivió plantea Aldo Mazzucchelli en su definición de ensayo biográfico, sino por la potencia imaginaria que une la obra y la vida del biografiado.

El arte del biógrafo consiste justamente en la astucia de la selección, señala Schwob, en su manera de elegir, de sintetizar el proceder de un hombre. Baigorria, entonces, va a seguir un hilo narrativo que lo guiará en la investigación de la vida de su biografiado y en la escritura de este libro que no se basa en ninguna cronología convencional ni en la recopilación o la exhaustividad de los datos: le importa cómo fue que Sánchez decidió 
abandonar la escritura, qué impulso íntimo o ético le hizo dejar de escribir. En Bartleby y compañia, Enrique Vila-Matas arma una biblioteca de libros en blanco en la que acumula una serie de escritores que han dejado de escribir e indaga entorno a distintos motivos que los condujeron a esa circunstancia: la falta de inspiración, la muerte de quien se ama, una admiración tal por otros escritores que ciega y enmudece, la falta de imaginación, etc. El impulso que lleva a Baigorria a escribir sobre Sánchez no es sin embargo la búsqueda de un motivo tal como lo hace Vila-Matas, sino el encuentro con eso que ya no puede ser. Sánchez dejó de escribir por el simple hecho de que como su literatura se había basado siempre en su vida, en un momento experimentó que ya no tenía más nada que decir. "Nunca en mi vida inventé una historia”, le dijo a Laureano Ortiz. "Todo ha sido en base a mi vida presente o pasada" (2012: 15). Sánchez se esfuma como escritor, se fuga de la escritura en búsqueda de una conciencia espiritual, a la retaguardia del armenio Jorge Ivanovitch Gurdjieff, un líder mítico, un gurú.

La gran pregunta de Sobre Sánchez, la que incita a Baigorria a seguir "remando" ${ }^{2}$, a armar una cronología, aunque inexacta y con baches profundos, de la vida del biografiado, es cómo Sánchez se fugó, cómo su figura de escritor desapareció de la escena literaria. Una biografía que, para el propio Baigorria, se cruza con la novela y el ensayo, y que, según él, no puede ser concebida como tal porque hay una época de la vida de Sánchez, la de sus años como linyera, que no puede rastrear del todo y que han quedado lagunas por conocerse.

\footnotetext{
Para una biografía que crea saber algo, no de una historia de vida, sino de la doctrina de su propio arte, debería investigarse mucho más de lo que puedo desde mis limitados recursos en esta isla del delta del Paraná, sin ningún financiamiento, liberado a mi audacia o a mi suerte. Debería poder cartografiarse los puntos de contacto entre vida y obra en aquel trayecto nómade. Lejos de aspirar a esa odisea, desde aquí sólo puedo seguir, en la medida de lo posible, el paso de Sánchez en la identificación de su búsqueda, renuncia, deserción y abandono de la escritura (2012:38).
}

En Trois ans avec Derrida, Peeters enseña que una biografía está hecha de llenos y de vacíos: hay algunos testimonios que hablan por voluntad propia y otros que rechazan el encuentro, así como algunos documentos permanecen inaccesibles. No se trata de un puzzle, de ir encontrando las piezas para armar una vida, sino que se inventa a medida que se escribe, justamente porque no puede completarse. No hay, dice Peeters, y no puede haber una biografía definitiva, ni tampoco un retrato supremo (2010: 66). También Fontana cuestiona la idea de una biografía total, capaz de representar por entero la complejidad de una vida. “ ¿Cuánta totalidad es necesaria?”, se pregunta Fontana, para considerar un relato como biografía. ¿No se escribe siempre desde un punto de vista, con una mirada en particular sobre el sujeto en cuestión? Aquello que pretende consignarse como una falta constituye, en realidad, la esencia del género: la fuerza de la selección. Escribir sobre la vida de alguien sin poder dar cuenta de la totalidad de su vida, escribir desde el comienzo renunciando a esa idea y dando por perdida toda pretensión de exhaustividad se convierte en este caso en una estrategia del biógrafo, quien escribe desde el Tigre sin demasiadas ganas ni recursos una biografía que no pensó iba a llevarle tanto trabajo. Un biógrafo que se la pasa remando para comprender la renuncia indeclinable de su biografiado:

O sea: ando a tientas, gateo, me muevo por olfato, balbuceo algunas referencias por oído o intuición, no entiendo nada de Literatura (mayúscula intencional) pero entiendo, por un lado, que para Sánchez la escritura fue un modo de escapar a la cárcel del sentido, y por el otro, que la fusión entre autor y narrador puede ser pertinente para el caso (2012: 17).

Sobre Sánchez no es una biografía ladrillo, de esas que tienen 1000 páginas y no se pierden datos ni certezas sobre el biografiado. No es tampoco un exponente de la forma canónica del género que Antonio Marcos Pereira caracteriza en el artículo de este dossier. Baigorria explota la rareza de Sánchez, el rasgo que lo hace único, un escritor linyera, un escritor a la intemperie que se dio a la fuga. El balbuceo de Baigorria, entonces, lejos de consignarse como una falta, es lo que le permite al biógrafo entrar en intimidad con su biografiado. De este modo, Baigorria ingresa a una tradición emergente de la biografía en América Latina. Una tradición que reúne biografías literarias de escritores que deciden indagar en las vidas de otros escritores y que ponen en funcionamiento, de ese modo, mecanismos diversos como los de la autofiguración además de ciertas decisiones selectivas y depurativas tendientes a construir una imagen de autor, propia y ajena. Esa tradición la 
encabeza Fernando Vallejo con sus dos monumentales biografías escritas sobre José Asunción Silva y Porfirio Barba Jacob, escritas a fines de los 80, y la continúan Jorge Edwards, Carlos María Domínguez, Santiago Roncagliolo, Ricardo Strafacce, y Osvaldo Baigorria. El hecho de que estos sean escritores que escriben sobre autores consagrados de las letras nacionales por el motivo que sea, - por el deseo de reivindicar una figura, por un encargo editorial, o por el impulso de escribir sobre vidas ajenas - implica un movimiento en la constitución y la invención de imágenes autorales. Julio Premat explica, en Héroe sin atributos, que el autor es un concepto diacrónico y relacional en tanto son autores los que preceden la propia creación, los que arman la red de filiaciones, de rebeliones edípicas, de parricidios y expiaciones (2009: 27). Si esta es, en definitiva, una tendencia actual de las biografías en América Latina, y Sobre Sánchez viene a iluminar un proceso constitutivo del género, habría que evaluar si el desafío de los biógrafos actuales que publican biografías literarias de escritores que los preceden, que fueron sus maestros, sus héroes literarios, que forman parte de una tradición nacional (ya sea para sacralizar o para derrumbar) es el armado de una Biblioteca de la Nación. Además de escribir sobre aquel que puede adquirir el lugar del precursor de la propia obra literaria e ir en búsqueda de un lugar consonante en la tradición nacional, la biografía de Sánchez traza el perfil de un excéntrico, y Baigorria lo hace visible a través de su rareza, de la fuga paradójica hacia otro lugar lejos de la literatura.

\section{"No tengo nada que decir pero lo estoy diciendo"}

Es como un fractal, cada fuente me remite a otra y otra más. A mí también me gustaría cantarle al ocio pero hay que trabajar mucho para acercarse a la experiencia vivida por otro. Me pregunto hasta dónde, si es posible aproximarme o si no estaré proyectando mis propios fantasmas sobre los agujeros negros que deja la estela de una vida pasada. Pero no tengo más remedio que intentarlo (2012: 25).

La relación del biógrafo con su sujeto es el corazón de la empresa biográfica. Todos los teóricos sobre biografía han hecho hincapié en este vínculo, ya sea con la intención de prevenir sobre la fascinación que puede suscitar el biografiado, ya sea para explicar la relación entre ambos. Más allá de todas las prevenciones, la escritura promueve ese movimiento hacia el otro, que afecta al yo. Y lo hace tender a la identificación con el biografiado. ¿Cuál es la relación que se construye entre Baigorria y Sánchez? El encuentro de Baigorria con Sánchez está fallado de entrada: lo ve por primera vez en una foto que acompañaba un artículo sobre él. Una foto de un hippie que no era Sánchez. Y cuando comienza a leerlo: "Doy fe: después de Nosotros dos traté de pasar a la lectura de El ambor... y me volví loco. No entendía nada. Tal vez tendría que haber ido más despacio [...]." (2012: 16). A pesar de esos desencuentros, biógrafo y biografiado terminan escribiendo juntos ("en compañía”, dice Peeters) el libro último que Sánchez no quiso o no pudo escribir. En este sentido, me parece interesante la referencia al vínculo entre el abogado y el escriba en "Bartleby" de Melville, que Gilles Deleuze, Giorgio Agamben y José Luis Pardo supieron analizar. El abogado de Melville, como el biógrafo Baigorria, entran en contacto con un sujeto que renuncia, que ya no quiere escribir más. Desarmado, desamparado, estupefacto y protestón, Baigorria intenta comprender a Sánchez. Reconoce que tiene muy poco que decir y se lamenta de la poca información con la que cuenta, pero aun así continúa con la tarea: "no tengo más remedio que intentarlo". En tanto relatos de vida, las biografías de Sánchez y de Bartleby no pueden hacerse. De Bartleby no hay nada qué contar, excepto la insistencia en el no; y de Sánchez no pueden reponerse los años como vagabundo. Baigorria se pierde y decide, como el abogado, sólo seguir sus pasos en el abandono de la escritura. En "Bartleby o la fórmula" Deleuze propone que para que haya identificación entre el abogado y el escriba (entre biógrafo y biografiado) tienen que cumplirse tres instancias: una forma, una imagen, un retrato o un modelo; un sujeto; y un esfuerzo del sujeto por adquirir la forma, por apropiarse de la imagen. En esa identificación, que Deleuze propone para explicar la relación entre los personajes del cuento, se genera una zona de indistinción, de ambigüedad entre el sujeto y su modelo que no es de similitud, de filiación natural ni de mímesis, sino de una extrema cercanía, como un deslizamiento, una contigüidad absoluta. De esa relación de cercanía, biógrafo y biografiado no pueden sino salir transformados. Sánchez es una pérdida irremediable 
para la literatura, y por lo tanto, no hay posibilidad de que su vida pueda ya convertirse en escritura. Como su literatura se basó siempre en su vida, Sánchez ya no sabe más que contar. Así, no es de la falta de datos de la que sufre el biógrafo Baigorria, sino de la radical incompatibilidad entre la vida de Sánchez y la literatura, en los términos que Pardo aplicó a "Bartleby" (2011: 147). Por esta misma razón, cuando decimos que Baigorria no encuentra la forma para dar cuenta del biografiado, pensamos que hay algo en la vida y la escritura de Sánchez que no se deja reducir a los imperativos genéricos. La renuncia a escribir una biografía, a la que se refiere en "About", es la dimisión por hacer literatura de un hombre que prefirió dejar de escribir. Sin literatura, no hay biografía. Aún menos habrá una biografía total.

Y preso de ese impulso por continuar, Baigorria se contagia de las manías de Sánchez, se deja arrastrar por sus fantasmas, se "identifica" con él, se desliza por una vida otra que en esas notas al pie termina siendo la propia. Habría que reparar en que las notas al pie no figuran, como dije antes, al pie del texto, sino que configuran un capítulo final y separado. Ubicarlas en esa posición resulta una decisión discutible, dado su cariz conservador. El riesgo de mantenerlas al pie del texto sobre Sánchez hubiese sido que la vida del biógrafo (lo autorreferencial) se superpusiese, y hasta devorase la vida del biografiado. Dos vidas en simultáneo entrelazadas que se complementarían, se tensionarían, se contorsionarían para sobrevivir en la literatura, a pesar de la fuga, traspasando la fiaca.

El gesto de renunciar a escribir, de preferir no hacerlo se configura en una imagen de artista, compartida por Baigorria y Sánchez. Baigorria se cansa de investigar sobre la vida del biografiado, a menudo prefiere hacer otra cosa antes que escribir o movilizarse para buscar más información sobre él. ¿Por qué insisto en encontrar el sentido a una vida ajena? ¿Qué sentido tiene seguir escribiendo si ya no tengo más que contar? "Entonces: habría que premiar a Néstor Sánchez por su silencio, por recordarnos que escribir es algo a abandonar cuando uno se queda sin ganas o porque la gana se le da. Por quedarse sin épica pero no sin ética. Seguro, es sólo mi mirada sobre él, no la posta" (2012: 76).

El sentido que Baigorria encuentra, en un primer momento, es el de la identificación inmediata con quien cree que tiene muchas cosas en común: la vida afuera, Estados Unidos, la vuelta al país de origen; identificación que inmediatamente se debilita cuando empieza a leer sus textos -“¿Qué carajo dice?”- Más tarde, después de la fuerza del primer encuentro, ese contacto toma forma en la reconstrucción del trayecto fugitivo del autor, de su devenir vagabundo, de su vida a la intemperie. El relato es la historia de esa pérdida, la pérdida de la cordura, el abandono voluntario del hogar, la pérdida para la literatura. No cuenta cómo se perdió eso sino más bien cómo se encontró con eso que ya se había perdido. Esas inclinaciones al "no" son las que a Baigorria le interesan, sobre las que ya había escrito en Anarquismo trashumante: el croto, explica, es el que siguió voluntariamente el rastro que lo llevaría a un lugar de no pertenencia. Su estilo es el de la renuncia, no el del despido.

Baigorria y Sánchez se hacen compañía y escriben juntos en los momentos en que los modos de hacer literatura se acercan. "Ley de tres", una historia en la que Sánchez trabajó sobre algo que le sucedió realmente, podría corresponder a Llévatela amigo: dos mujeres y un hombre que se enamoran y viven juntos. "Ley de tres" cuenta lo que pudo ser y no fue, el encuentro entre Vicky, Cecilia y Néstor. Llévatela amigo, a la que Baigorria hace referencia en la nota número nueve, explora los deseos más íntimos de fuga, los impulsos por desplazarse por nuevas experiencias y fantasías. Dos relatos en los que confluyen vida y literatura. Y vuelven a escribir juntos los episodios en los que se renuncia a algo, en los que se dice que no, porque en definitiva en la biografía surge el efecto contagio, y el biógrafo termina viviendo la vida del otro, o la que el otro hubiese querido vivir. Baigorria padece la locura y la misma inclinación a renunciar que Sánchez. "Lo que pasa es que mi compromiso con el objeto Sánchez llegó a ser tan obsesivo que temo haberme expuesto al contagio. No de una prosa sino de un aura" (2012: 152). Mientras escribía la biografía, cuenta en las notas al pie, comenzó a sentirse mal, a tener dolores y decidió consultar un médico, decisión que también le costó trabajo: salir de la isla, hacerse exámenes, esperar, etc. Finalmente, esos análisis dieron bien, pero le recomendaron un psiquiatra 
que le recetó antidepresivos: Sánchez atravesó la locura, la esquizofrenia, el delirio místico, la acidia, la falta extrema de voluntad.

La transferencia fue total: el abandono persigue también la escritura de Baigorria. A pesar de preferir no hacerlo, de verse sometido al sinfín de inconvenientes que le provocó la investigación sobre Sánchez no pudo dejarlo y continuó hasta terminar (a medias porque, desde su punto de vista, no pudo escribir esa biografía que hubiese querido ni contar la auténtica experiencia de Sánchez). "Así voy. Con ligeras fallas de diseño, enfermedades a la larga, pero todavía en marcha” (2012: 164). Si la biografía fue, como alega Baigorria, por encargo editorial, podría haber dicho que no, pero el biógrafo no es un desertor, no puede dejarlo todo: se fue pero volvió, prefiere no escribir pero escribe, dice que no tiene nada que decir, pero, en definitiva dice. Fue desafiado por una afinidad que, según dice el biógrafo estadounidense Schorer: "Al ir aprendiendo acerca de él con toda su obstinada deficiencia en su conocimiento de sí mismo, creo que gané en conocimiento de mí mismo" (Edel 1990: 61). Baigorria es más bien un perezoso, alguien que hace las cosas en contra de su propia voluntad, porque nunca tiene muchas ganas. Baigorria experimenta uno de los tantos momentos de la escritura, según Barthes en "Fragmentos de un discurso perezoso", el de la pereza. Instancia que tiene su cura, y que es capaz de atravesar ese "no" que lucha por imponerse. Coquetea con el naufragio y sigue remando:

Me voy de tema, pierdo la pista, me deslizo o desbarranco; parte de los efectos de acercarme a una figura tan extrema de escritor o ex escritor como la que tengo en frente, es el derrape. Quizá no estaba preparado para encarar la tarea, no tenía el training, la sensibilidad adecuada. Igual, yo remo (2012: 12).

\section{BIBLIOGRAFÍA}

Baigorria, Osvaldo (2005). Correrias de un infiel. Buenos Aires, Catálogos.

Baigorria, Osvaldo (2015). Llévatela amigo por el bien de los tres, Buenos Aires, Caja Negra.

Baigorria, Osvaldo (2008). Anarquismo Trashumante. Crónicas de crotos y linyeras, La Plata, Terramar.

Baigorria, Osvaldo (2014). Con el sudor de tu frente. Argumentos para la sociedad del ocio, Buenos Aires, Interzona.

Baigorria, Osvaldo (2012). Sobre Sánchez, Buenos Aires, Mansalva.

Cueto, Sergio (2008). "Variaciones sobre Bartleby”, en Melville, Herman, Bartleby, Trad. Jorge Luis Borges. Rosario, Editorial Serapis, pp.117-130.

Deleuze, Gilles (2011). “Bartleby o la fórmula”, en AA.VV Preferiria no hacerlo, Valencia, Pre-textos, pp.57-93.

Dosse, François (2007). El arte de La biografía, México, Universidad Iberoamericana.

Edel, Leon, (1990). Vidas ajenas. Principia biographica, traducción de Evangelina Nuño de la Selva, Buenos Aires, Fondo de Cultura Económica.

Fontana, Patricio, Vidas americanas. Usos de la biografia en Domingo Faustino Sarmiento, Juan Bautista Alberdi y Juan Maria Gutiérrez, Eudeba (en prensa).

Holroyd, Michael (2011). Cómo se escribe una vida, Ensayos sobre biografia, autobiografía y otras aficiones literarias, Buenos Aires, La Bestia Equilátera.

Mckensie, César (2013). "Ceremonias del exhumador: lectura descriptiva de El mensajero y Chapolas negras" en Girardo, Luz Mary y Salamanca-León, Néstor (ed.), Fernando Vallejo. Hablar en nombre propio. Bogotá, Universidad Nacional de Colombia.

Mazzucchelli, Aldo (2016). “La biografía y su forma. Una lectura de Adorno”, en Actas IV Coloquio Internacional "Literatura y Vida", CELA, 2016. Disponible en: http://www.celarg.org/int/arch_coloquios/mazzucchelli.pdf

Pardo, José Luis (2011). "Bartleby o de la humanidad », en AA.VV. Preferiría no hacerlo, Valencia, Pre-textos.

Peeters, Benoît (2010). Trois ans avec Derrida, les Carnets d'un biographe, Paris, Flammarion.

Podlubne, Judith (2016) “La biografía como forma”, Ponencia presentada en el Congreso Argentino de Literatura, Santa Fe, 2016. 
PREMAT, Julio (2009). Héroes sin atributos, figuras de escritor en la literatura argentina, Buenos Aires, Fondo de Cultura Económica.

Schwob, Marcel (1998). "El arte de la biografía", en AA.VV. El arte de la biografía, Madrid, Conaculta Océano, pp. 399-406.

\section{Notas}

1 Del último capítulo de mi tesis doctoral Autoficción y melancolía en la narrativa de Fernando Vallejo (Rosario, Beatriz Viterbo, 2017), que precede a este trabajo, se desprende el interés por estudiar un género cercano y vecino a las escrituras autobiográficas: la biografía. En ese capítulo se trabaja la escritura biográfica de Fernando Vallejo que retrata la vida de dos poetas coterráneos del siglo XIX: José Asunción Silva y Porfirio Barba Jacob, y de un gramático, Rufino José Cuervo. Me interesaba la construcción de figuras ajenas a partir de la propia y la constitución de un biógrafo impertinente que no sólo se mete en la vida de los otros sino que las utiliza para seguir fabulando sobre la suya.

2 Utilizo el verbo remar porque resulta una constante en la biografia: para poder escribir, Baigorria decide aislarse y se muda a una casa en el Tigre, en medio de la isla. Pero ese punto de fuga se le convierte en un problema más, en un obstáculo para la escritura. Sin buena señal de internet, sin puntos de conexión con el afuera, y con el agua en los talones, la investigación sobre Sánchez no se le facilita. Para salir de la isla hay que remar, para saber más sobre la vida de otro, para escribir, no hay que fugarse, hay que trabajar.

3 Ver artículo publicado en este dossier. 